\section{Successful Desensitization for Hydroxychloroquine Anaphylaxis}

\section{To the Editor:}

Hydroxychloroquine (HCQ) is an antimalarial agent with immunosuppressive and cytotoxic properties. HCQ is a cornerstone in the treatment of systemic lupus erythematosus (SLE) and rheumatoid arthritis ${ }^{1,2}$. It has multiple beneficial effects. Exanthema/rash is the most common side effect. About $10 \%$ of patients treated with HCQ develop skin eruptions, some due to hypersensitivity. Other patterns of cutaneous hypersensitivity reactions have also been described with antimalarials ${ }^{1,2}$.

Our patient, a 48-year-old man, had had as many as 11 attacks of pericarditis in less than 2 years, leading finally to a diagnosis of SLE. Once treatment with HCQ was initiated, there were no further attacks. He received treatment with HCQ over a period of 6 months with no notable incident. It was then necessary to interrupt the HCQ for approximately 2 weeks due to an intercurrent illness. Coinciding with resumption of treatment with HCQ $200 \mathrm{mg}$, he showed symptoms of anaphylaxis (blood pressure alterations, generalized urticaria, and chest pains) and required attention in the emergency room. He was referred to the Allergy Unit. Anaphylaxis due to HCQ was diagnosed, based on positive skin tests, and HCQ was stopped.

On 3 occasions during the 3-month period when he was without treatment with HCQ, he required treatment using cycles of oral corticoids due to reappearance of pericarditis symptoms. He declined to take corticosteroids on a longterm basis although the progression of his pathology made this appear to be necessary. Faced with the negative clinical situation and the lack of longterm treatment alternatives that would be as efficient and safe as HCQ, the patient and his rheumatologist asked us to carry out a desensitization procedure.

The patient was informed that there existed no previous protocols for desensitization with this drug and of the high risk involved in such a procedure. A written consent document was signed and it was decided that the procedure be carried out close to the Intensive Care Unit (ICU), without hospitalization but with the patient monitored and with a peripheral intravenous line.

In order to determine the initial dose, skin-prick tests were carried out with duplicate 10-fold serial dilutions of HCQ. Dilutions in saline solution of $0.002,0.02,0.2,2.0$, and $20.0 \mathrm{mg} / \mathrm{ml}$ were used. Ten control procedures were also carried out using atopic and non-atopic subjects. Skin test results are shown in Table 1.

The procedure commenced with an oral dose of $0.2 \mathrm{mg}(1 \mathrm{ml}$ of the solution of $0.2 \mathrm{mg} / \mathrm{ml}$ ). This concentration had produced a papule that was similar to that produced by the saline solution used as a negative control. See Table 2 for details of the procedure.

It was decided that a procedure of weekly increases be followed. Tryptase control procedures were carried out before and after the increase in the dose. On the following day, in the Allergy Unit, the patient repeated the last dose tolerated on the previous day, this being the dose that he was

Table 1. Result of skin tests.

Before Procedure

Papule Diameter, $\mathrm{mm}$ Papule Diameter, $\mathrm{mm}$

\begin{tabular}{lcc}
\hline Histamine $10 \mathrm{mg} / \mathrm{ml}$ & $10 \times 10$ & \\
Saline solution & 4 & \\
HCQ & 42 & 42 \\
$20 \mathrm{mg} / \mathrm{ml}$ & 30 & 20 \\
$2.0 \mathrm{mg} / \mathrm{ml}$ & 4 & 4 \\
$0.2 \mathrm{mg} / \mathrm{ml}$ & 4 & 4 \\
$0.02 \mathrm{mg} / \mathrm{ml}$ & 4 & 4 \\
$0.002 \mathrm{mg} / \mathrm{ml}$ & &
\end{tabular}

HCQ: hydroxychloroquine. to take at home each day for the following 6 days. After 4 sessions the maintenance dose was reached.

The skin test study with HCQ was repeated at the different concentrations after completing the procedure, having reached the dose of $100 \mathrm{mg}$.

The HCQ skin tests showed dose-dependent sensitivity to the product. All skin tests in atopic and non-atopic control subjects were negative.

The patient tolerated the desensitization procedure with no incidents. A dose of $100 \mathrm{mg}$ /day was reached in 4 sessions. No changes were observed in the tryptase values before or after the dose increases. The skin tests carried out at the end of the process of desensitization, with the same 10-fold serial dilutions, were totally negative, all the dilutions producing a papule similar to that of the saline solution.

From a clinical point of view the patient has progressed favorably. Over a period of 9 months, he has been treated with HCQ $100 \mathrm{mg}$ per day, showing no further disease symptoms.

HCQ is pivotal in the treatment of rheumatological disease. Since no other available option was comparable to HCQ in terms of efficacy/safety in the long term, it was decided that desensitization to HCQ should be tried in the allergic patient. Desensitization to a number of medications is performed under circumstances where no good alternative is available for an allergic patient. Such procedures have been carried out for decades with patients allergic to penicillin ${ }^{3}$. In recent years numerous publications have referred to procedures of desensitization to chemotherapy drugs carried out with success, safety, and efficacy in numerous patients ${ }^{4,5,6}$. We found only one study of desensitization to $\mathrm{HCQ}^{7}$, involving 4 patients who developed a rash coinciding with administration of the drug, and who then tolerated the procedure. However, with the exception of one patient in whom the rash reappeared when HCQ was reintroduced, in the remaining 3 patients there are no data to confirm hypersensitivity to HCQ and which would consequently allow use of the term desensitization according to Sontheimer ${ }^{8}$.

The mechanism by which tolerance is induced is not fully understood. Both mastocytes in the blood and cutaneous mastocytes became tolerant. This is shown by the negative results of the HCQ skin tests carried out after desensitization, proving the success of the procedure.

The induction of tolerance does not affect the therapeutic effects. Our patient's progression was very favorable with the treatment.

This relatively short oral procedure of 28 days, without hospitalization, proved to be efficient and safe. No reactions of any type were observed. It is probable that the success of this study was partly the result of simultaneous treatment with nonsteroidal antiinflammatory drugs on a daily basis. Pretreatment with acetylsalicylic acid and montelukast has proven to be a good measure in rapid desensitization procedures ${ }^{9}$. Both pretreatments improve tolerance to these procedures by decreasing the number of reactions and consequently decreasing the use of corticosteroids and antihistamines. At the time of writing, the patient continues to tolerate without incident.

This is the first documented case of anaphylaxis due to an allergy to HCQ involving an IgE mechanism. We found no cases in the literature of anaphylaxis due to HCQ. This is also the first case of successful HCQ desensitization as the result of a 4-week procedure not involving hospitalization.

Reactions to drugs where a case of hypersensitivity is suspected should be referred for an allergological study. Many cutaneous drug reactions are self-limiting; however, a priori, it is not possible to know in which cases this will be so. In the case of reactions to HCQ that could lead to temporary or permanent interruption of treatment with this highly efficient and safe drug, it is advisable to consult allergy units specialized in study and treatment of drug-related reactions, in order to establish in which patients it is acceptable to cautiously reintroduce the drug, and those in which it is necessary to carry out a desensitization procedure.

Note added in proof: Our patient came for a followup in March 2010, his rheumatologist having requested an increase in drug dose. In January 2010 he had started to experience pains in muscles and joints, and in February

Personal non-commercial use only. The Journal of Rheumatology Copyright @ 2010 . All rights reserved. 
Table 2. Desensitization procedure.

\begin{tabular}{|c|c|c|c|c|c|}
\hline $\begin{array}{l}\text { Concentration of HCQ } \\
\text { in Saline Solution, } \mathrm{mg} / \mathrm{ml}\end{array}$ & Day & $\begin{array}{c}\text { Volume } \\
\text { Administered, } \mathrm{ml}\end{array}$ & $\begin{array}{c}\text { Dose, } \\
\mathrm{mg}\end{array}$ & $\begin{array}{c}\text { Dose } \\
\text { Accumulated } \\
\text { per Day, mg }\end{array}$ & Location \\
\hline \multirow[t]{3}{*}{0.2} & 1 & 1 & 0.2 & & ICU \\
\hline & & 2.5 & 0.5 & & ICU \\
\hline & & 5 & 1 & & ICU \\
\hline 2 & & 1 & 2 & 3.7 & ICU and repeated in the unit \\
\hline 2 & & $1 / 24 \mathrm{~h}$ & $2 \mathrm{mg} / 24 \mathrm{~h}$ & & At home daily \\
\hline \multirow[t]{3}{*}{2} & 7 & 1 & 2 & & At home \\
\hline & & 2 & 4 & & ICU \\
\hline & & 4 & 8 & & ICU \\
\hline 20 & & 0.6 & 12 & & ICU \\
\hline \multirow[t]{2}{*}{20} & & 1 & 20 & 46 & ICU and repeated in the unit \\
\hline & & $1 / 24 \mathrm{~h}$ & $20 \mathrm{mg} / 24 \mathrm{~h}$ & & At home daily \\
\hline \multirow[t]{2}{*}{20} & 14 & 1 & 20 & & At home \\
\hline & & 15 & 30 & & $\mathrm{ICU}$ \\
\hline \multirow[t]{2}{*}{20} & & 2.5 & 50 & 100 & ICU and repeated in the unit \\
\hline & & $2.5 / 24 \mathrm{~h}$ & $50 \mathrm{mg} / 24 \mathrm{~h}$ & & At home daily \\
\hline \multirow[t]{2}{*}{20} & 21 & 2.5 & 50 & & At home \\
\hline & & 2.5 & 50 & & ICU \\
\hline \multirow[t]{2}{*}{12.5} & & 13 & 81 & 181 & ICU \\
\hline & & $1 / 2$ pill & 100 & & $\begin{array}{l}\text { Allergy Unit and repeated } \\
\text { at home daily }\end{array}$ \\
\hline
\end{tabular}

HCQ: hydroxychloroquine; ICU: Intensive Care Unit.

suffered another episode of pericarditis. In March we carried out a 2-week desensitization procedure to increase the dose to $200 \mathrm{mg} /$ day. The patient tolerated the treatment without incident. He is currently being treated with $200 \mathrm{mg} /$ day and awaiting a followup examination in 3 months.

CARMEN DÍAZ DONADO, PhD; ELENA MAQUIERA DÍEZ, MD, Allergy Unit, Hospital Universitario Central Asturias, Oviedo, Spain. Address correspondence to Dr. C.D. Donado, Doctor Bellmunt s/n, Oviedo 33006, Asturias, Spain. E-mail: cdiazd@ seaic.es

\section{REFERENCES}

1. Rynes RI. Antimalarial drugs in the treatment of rheumatic deseases. In: Rose BD, editor. Wellesley, MA: UpToDate; 2010.

2. Felson DT, Anderson JJ, Meenan RF. The comparative efficacy and toxicity of second-line drugs in rheumatoid arthritis. Results of two metaanalyses. Arthritis Rheum 1990;33:1449-61.

3. Garai F, Montgomery RM. Further successful desensitization to penicillin. NY State J Med 1953;53:448.

4. Lee CW, Matulonis UA, Castells MC. Rapid inpatient/outpatient desensitization for chemotherapy hypersensitivity: standard protocol effective in 57 patients for 255 courses. Gynecol Oncol 2005;99:393-9.
5. Castells MC, Tennant NM, Sloane DE, Hsu FI, Barrett NA, Hong DI, et al. Hypersensitivity reactions to chemotherapy: outcomes and safety of rapid desensitization in 413 cases. J Allergy Clin Immunol 2008;122:574-80.

6. Macy E, Bernstein JA, Castells MC, Gawchik SM, Lee TH, Settipane RA, et al; Aspirin Desensitization Joint Task Force. Aspirin challenge and desensitization for aspirin-exacerbated respiratory disease: a practice paper. Ann Allergy Asthma Immunol 2007;98:172-4

7. Mates M, Zevin S, Breuer GS, Navon P, Nesher G. Desensitization to hydroxychloroquine - experience of 4 patients. J Rheumatol 2006;33:814-6.

8. Sontheimer RD. Desensitization to hydroxychloroquine: alternative interpretations. J Rheumatol 2007;34:253-5.

9. Breslow RG, Caiado J, Castells MC. Acetylsalicylic acid and montelukast block mast cell mediator-related symptoms during rapid desensitization. Ann Allergy Asthma Immunol 2009; 102:155-60.

J Rheumatol 2010;37:9; doi:10.3899/jrheum.091453 